\title{
Correction to: Age Patterns in Risk Taking Across the World
}

\author{
Natasha Duell ${ }^{1} \cdot$ Laurence Steinberg $^{2} \cdot$ Grace Icenogle $^{1} \cdot$ Jason Chein $^{1} \cdot$ Nandita Chaudhary $^{3} \cdot$ Laura Di Giunta $^{4}$. \\ Kenneth A. Dodge ${ }^{5}$. Kostas A. Fanti ${ }^{6}$. Jennifer E. Lansford ${ }^{5}$. Paul Oburu ${ }^{7}$. Concetta Pastorelli ${ }^{4} \cdot$ Ann T. Skinner $^{5}$. \\ Emma Sorbring $^{8}$. Sombat Tapanya ${ }^{9} \cdot$ Liliana Maria Uribe Tirado $^{10} \cdot$ Liane Peña Alampay $^{11} \cdot$ Suha M. Al-Hassan ${ }^{12}$. \\ Hanan M. S. Takash ${ }^{13} \cdot$ Dario Bacchini $^{14} \cdot$ Lei Chang $^{15}$
}

Published online: 28 February 2019

(c) Springer Science+Business Media, LLC, part of Springer Nature 2019

Correction to: Journal of Youth Adolescence (2018) 47 (5):1052-1072

https://doi.org/10.1007/s10964-017-0752-y

In the original publication, the legends for Figs 4 and 5 were incorrect, such that each regression line was mislabeled with

The original article can be found online at https://doi.org/10.1007/ s10964-017-0752-y

Natasha Duell

ntduell@temple.edu

1 Department of Psychology, Temple University, Philadelphia, PA, USA

2 Department of Psychology, Temple University and King Abdulaziz University, Philadelphia, PA, USA

3 Department of Human Development and Childhood Studies, Lady Irwin College, University of Delhi, New Delhi, India

4 Department of Psychology, Università di Roma "La Sapienza", Roma, RM, Italy

5 Center for Child and Family Policy, Duke University, Durham, NC, USA

6 Department of Psychology, University of Cyprus, Kallipoleos, Cyprus

7 Department of Educational Psychology, Maseno University, Maseno, Kenya the incorrect country. Below are the correctly labeled countries. The authors apologize for any confusion or misinformation this error may have caused.
8 Department of Psychology, University West, Trollhättan, Sweden

9 Department of Psychiatry, Chiang Mai University, Chiang Mai, Thailand

10 Consultorio Psicológico Popular, Universidad San Buenaventura, Medellín, Colombia

11 Department of Psychology, Ateneo de Manila University, Metro Manila, Philippines

12 Hashemite University and Emirates College for Advanced Education, Al Zafranah, Abu Dhabi, United Arab Emirates

13 Queen Rania Faculty for Childhood, Hashemite University, Zarqa, Jordan

14 Department of Psychology, University of Campania "Luigi Vanvitelli", Caserta, CE, Italy

15 Department of Psychology, University of Macau, Zhuhai Shi, China 
Fig. 4 Age patterns in selfreported health risk taking across countries. Values are percentage (\%) of health risks (drinking alcohol, getting in the car with a drunk driver, smoking cigarettes, and having unprotected sex) endorsed. Slopes represent estimated regression coefficients (centered at the slope for 10-year-olds) for age and age ${ }^{2}$ adjusted for gender, parental education, and intellectual ability. The model was estimated separately for each country. *Countries for which there was a significant quadratic effect of age
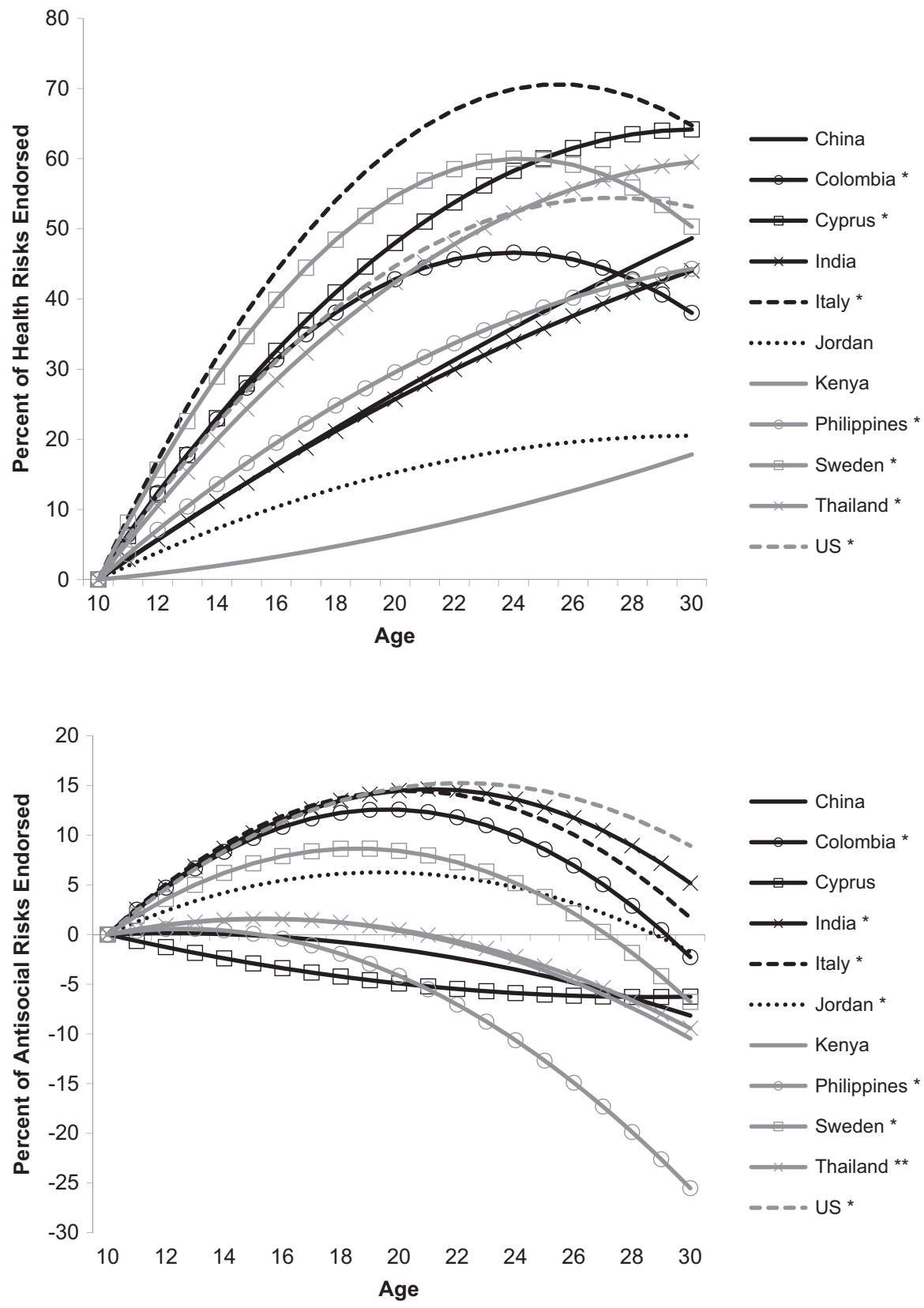

Fig. 5 Age patterns in selfreported antisocial risk taking across countries. Values are percentage $(\%)$ of antisocial risks (vandalizing, stealing, fighting, walking through a dangerous neighborhood, and threatening someone) endorsed. Slopes represent estimated regression coefficients (centered at the slope 10-year-olds) for age and age ${ }^{2}$ adjusted for gender, parental education, and intellectual ability. The model was estimated separately for each country. *Countries for which there was a significant quadratic effect of age. **The quadratic effect is significant for females, but not males 